\title{
HYDROTHERMAL CRYSTAL GROWTH AND APPLICATIONS
}

\author{
M. Prakasam ${ }^{1}$, O. Viraphong ${ }^{1}$ O. Cambon ${ }^{2}$ and A. Largeteau ${ }^{1}$ \\ ${ }^{1}$ CNRS, University of Bordeaux, ICMCB, 87 avenue du Dr. A. Schweitzer, Pessac, F-33608, France \\ ${ }^{2}$ Institut Charles Gerhardt UMR 525, Université Montpellier 2, Place Eugène Bataillon 34095, France
}

\section{ABSTRACT}

Hydrothermal crystal growth offers a complementary alternative to the conventionally used crystal growth techniques to synthesize new materials and grow bulk crystals for specific applications. These specialized techniques is often capable of growing crystals at temperatures well below their melting points and thus potentially offer routes to new phases or the growth of bulk crystals with less thermal strain. The hydrothermal process is utilized for growing a wide variety of crystals. Most of the electronic industry uses $\alpha$-Quartz due to its unique combination of piezoelectricity, high mechanical and chemical stability and very high mechanical coupling factor $(\mathrm{Q})$ at resonance and is a low cost producing method, due to the matured crystal growth technology developed since $1970 \mathrm{~s}$. With a melting point of $1706^{\circ} \mathrm{C}$ and high chemical resistance, quartz crystals would be very difficult to form by either melt or flux techniques. Since cooling through the transition point at $573^{\circ} \mathrm{C}$ usually produces twins, any technique for production of single crystals must be done below this temperature due to the transition between $\alpha$ and $\beta$-Quartz. Hydrothermal crystal growth helps in obtaining the crystals at temperatures lower than its transition temperature at high pressure. Here we present about hydrothermal growth of $\mathrm{Ge}$ doped $\mathrm{SiO}_{2}$ crystals for piezoelectric applications and the general principle of high hydrostatic pressure is discussed.

\section{INTRODUCTION}

Since $19^{\text {th }}$ Century, pressure in the scale of MPa to several GPa was developed to study the compressibility of gases and liquids. The development of high pressure in different scientific domains was strongly dependent on the knowledge of the associated technologies. High pressure has been implemented in various fields such as to study the geology of earth and develop diamond and Quartz $\left(\mathrm{SiO}_{2}\right)$ in industrial scale. Initially, high pressure was mainly used in synthesis of minerals from extraction of metals from ores and for crystal growth of $\alpha$ quartz called as hydrothermal crystal growth ${ }^{1}$. The growth of single crystals is an important process; the applications of such crystals are principally used in electronics $\left(\mathrm{Si}, \mathrm{SiO}_{2}\right)$ with carefully controlled purity which are difficult to obtain with ceramics or glasses.

Two major family of growth methods are most often employed for single crystals, namely, growth from solution and growth from melt. The less complex and most rapid single crystal growth processes employ crystallization from the melt, invented by Czochralski, Bridgman - Stockbarger, Verneuil, etc. In these processes, the crystal present the composition melted congruently (same crystalline phase before and after melting). The solidification occurs on an oriented seed crystal with same composition that is used. Some materials are incongruently melted (decomposition below melting point), under such a case the melt process cannot be used. The same applies where there is a strong tendency for glass formation from the melt, as it is for Quartz. Diamond is a special case in that it is only thermodynamically stable at high pressure. In solution single crystal growth processes, the precursor is dissolved in a liquid medium (or flux), different solution growth processes exist (without or with pressure to increase the dissolution). In order to avoid the aforesaid complexities involved in the conventional crystal growth techniques, hydrothermal technique can be employed as an alternative. 
Hydrothermal synthesis refers to heterogeneous reactions in aqueous media above $100^{\circ} \mathrm{C}$ and 1 bar. The term "hydrothermal" was first used by the geologist Sir Roderick Murchison to describe the action of water at elevated temperature and pressure leading to the formation of various rocks and minerals. Since1940, the improvement of the mechanical properties of alloys and consequently the requirement for improved high performance cutting and machining tools permit to improve technical developments for high pressure equipment for solid phase (Belt-type, Conac-type, multi-anvils, diamond anvil cell) or liquid phase (vessel). The first most important application of pressure in liquid phase obtained was $\alpha$ Quartz single crystal by hydrothermal crystal growth process. Conventionally hydrothermal method is used to initiate heterogeneous chemical reactions in the presence of aqueous solvents under pressure and intermediate temperature, which dissolves the solute particles and is capable of precipitating the dissolved solute particles with a gradient in temperature, which is impossible to obtain under ambient pressure and temperatures. Initially water was the only liquid that was considered for usage in the hydrothermal method, which resulted in very small size crystals, owing to the inherent low solubility of the solute. This resulted in searching for new solvents other than water. Single crystals of $\alpha$-Quartz obtained by various techniques have been reported in literature ${ }^{2-6}$. Single crystals of $\alpha$-Quartz are obtained generally with water and mineralizers dissolved in solvents, which could lead to the formation of color centers and parasitic phases. In the current article, we have explained the applicability of hydrothermal crystal growth for $\alpha$-Quartz doped with $\mathrm{GeO}_{2}$ to be employed in piezoelectric devices.

\section{EXPERIMENTAL PROCEDURE}

Hydrothermal crystal growth method is more analogous to crystal growth from aqueous solution at ambient temperature. Hydrothermal crystal growth is done in a closed vessel under pressure called "autoclave". The required quantity of aqueous solution is filled in the autoclave according to the pressure and temperature required following the thermodynamical conditions ${ }^{7,8}$ desired. The autoclave is heated in order to obtain the required temperature gradient. This temperature gradient helps in transporting the solute molecules from the hot zone to the cold zone by the convection process. The autoclaves are made to withstand the various constraints such as pressure, temperature and aggressive fluids over a long period of time. So the material constituting the autoclave should have adaptable characteristics. Most of the industrial autoclaves are made of steel. It is well known that the steel is an alloy based on Iron "Fe" which reacts with the solute upon reaction with aggressive solvents. This is mostly observed in the case of $\alpha$-Quartz crystal growth in the form of thin layer of $\mathrm{NaFeSi}_{2} \mathrm{O}_{6}$ (Acmite) on the internal wall of the autoclave, which is very difficult to remove when once formed. This makes "passivation" cycle necessary before using autoclave for the crystal growth; else this layer becomes too thick. When Acmite is thick inside the autoclave, it will lead to problem for experiment processing. Thermodynamical parameters such as $\mathrm{P}, \mathrm{T}$ and $\Delta \mathrm{T}$ govern to determine the crystal growth rate in addition to the diaphragm opening and the type of solvent used.

In order to grow single crystals of $\mathrm{SiO}_{2}$ doped with $\mathrm{GeO}_{2}$, It can be inferred from the phase diagram of $\mathrm{SiO}_{2}-\mathrm{GeO}_{2}{ }^{9}$ that the maximum content of $\mathrm{GeO}_{2}$ that can form single phase is 31 at $\%$ at about $700^{\circ} \mathrm{C}$ and $70 \mathrm{MPa}$ under hydrothermal conditions. Hydrothermal quartz crystals are generally grown with $\mathrm{NaOH}(1 \mathrm{M})$ and $\mathrm{Na}_{2} \mathrm{CO}_{3}(0.8 \mathrm{M})$ at about $150 \mathrm{MPa}$ and $360^{\circ} \mathrm{C}$. However these conditions doesn't apply for $\mathrm{Si}_{1-\mathrm{x}} \mathrm{Ge}_{\mathrm{x}} \mathrm{O}_{2}$ (SGO), because of the formation of sodium germinate which precipitate in the bottom of the autoclave. One of the possibilities to incorporate higher germanium content in $\alpha$-Quartz crystals is by processing the crystal growth experiment at high pressure $>250 \mathrm{MPa}$ and temperatures until $700^{\circ} \mathrm{C}$ with dilute aqueous alkaline or fluorides solutions. The aforesaid conditions are inappropriate to be 
employed to obtain large dimensions. The single crystals of SGO with the $\alpha$-Quartz type structure is obtained by using Nichrome alloy or stainless steel autoclaves. At ICMCB, hydrothermal crystal growth is carried out in the machine designed by M/S HP Systems, PERIGNY, France. Synthetic quartz oriented perpendicular to the Z-axis of the crystal is used as the seed. For the preparation of nutrient, $\mathrm{SiO}_{2}$ and $\mathrm{GeO}_{2}$ are mixed in the desired ratio, and then thermally heated either to form amorphous phase or cristobalite form. The temperature ranges from $300^{\circ} \mathrm{C}$ to $500^{\circ} \mathrm{C}$ and the pressure ranges from $100 \mathrm{MPa}$ to $300 \mathrm{MPa}$ to grow the Quartz single crystals with a temperature gradient between $10^{\circ} \mathrm{C}$ to $100^{\circ} \mathrm{C}$. Quartz crystals are grown on the seeds of oriented $\alpha$-Quartz single crystals, which are prepared by cleaning the surface of the seeds with $\mathrm{HF} / \mathrm{NaOH}$. Pure water is used as the solvent. High pressure crystal growth experiments to obtain SGO crystals were carried out in the autoclave at ICMCBCNRS, France (Fig. 1)designed and developed by M/S HP Systems, France, which is capable of working until $350 \mathrm{MPa}, 450^{\circ} \mathrm{C}$ with autoclave capacity of 1.51 .
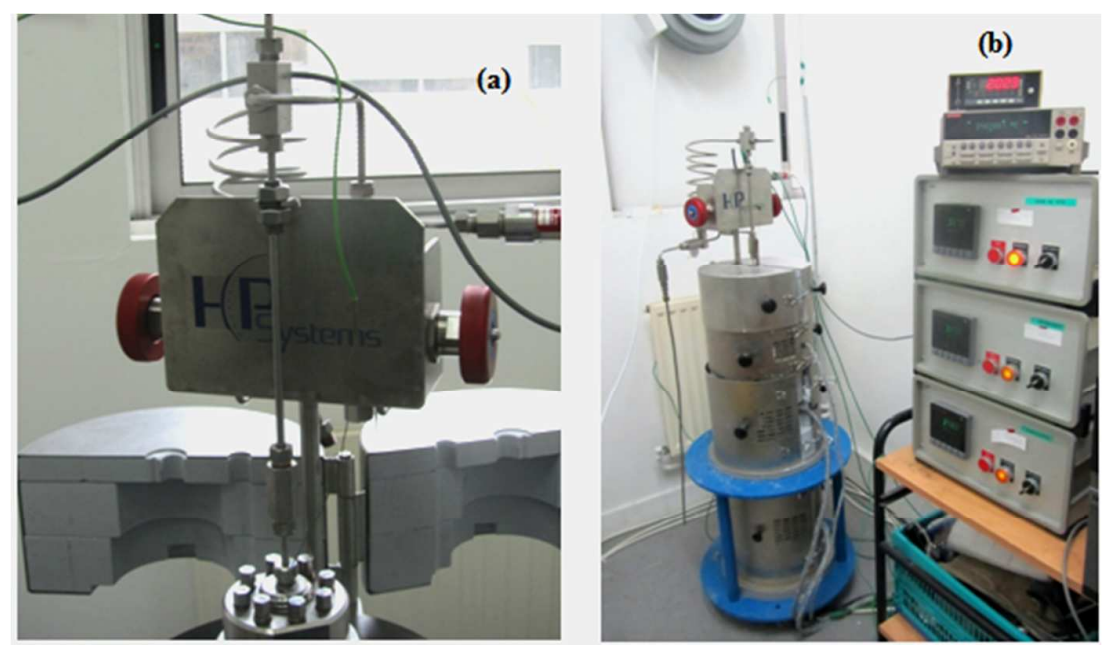

Figure1 (a). High pressure security valve system and (b) hydrothermal system interfaced with computer at ICMCB-CNRS

\section{RESULTS AND DISCUSSION}

$\mathrm{SiO}_{2}$ is found both in crystalline and amorphous form in nature. The stability of each of the structural forms of Quartz is different and well defined under equilibrium conditions. Crystalline quartz with its low temperature co-efficient will lead to a small change in resonant frequency with any difference in temperature with high $\mathrm{Q}$ factor at resonance. Presence of any defects such as impurities, cracks or air bubbles significantly reduces the Q-factor. With the help of optimizing the crystal growth parameters it is possible to avoid the defects that are observed in the natural crystals (in terms of composition and structure).

Most of the defects that are induced in the grown crystals also depend on the nutrient used or solvent used. The defects are also induced from the chemical corrosion caused from the wall of autoclave depending on the solvent and the metal of the autoclave. Fluctuations in the thermodynamical parameters governing the crystal growth and inclusions of foreign particles lead to structural defects in Quartz. Presence of the defects in quartz crystals alters the device properties to a greater extent. Additional benefits of growing the crystals by hydrothermal method is that the crystal grows under less thermal strain and therefore it is possible to control the stoichiometry by producing in the oxidizing or reducing conditions. Crystalline $\mathrm{GeO}_{2}$ has two structural polymorphs, such as $\alpha$-Quartz like $\left(\mathrm{P} 3_{2} 21\right)$ trigonal (hexagonal) structure and rutile type tetragonal $\left(\mathrm{P}_{2} / \mathrm{mnm}\right)$ structure. $\alpha$-Qquartz like structure 
of $\mathrm{GeO}_{2}$ has been demonstrated to exhibit stability at high temperature, but with basic differences in the structure. Structural difference essentially leads to the difference in the behavior of $\alpha$-Quartz $\mathrm{SiO}_{2}$ and $\mathrm{GeO}_{2}$ under high pressure, which arises from the rotation or tilting of the tetrahedral around the shared bridging oxygen. In particular, $\alpha$-Quartz like structure of $\mathrm{GeO}_{2}$ undergoes the compression by tilting of the tetrahedral makes germanate structure to undergo the pressure induced transformations at lower pressure than the $\alpha$-Quartz structure. The aforesaid can be verified from the transformation of $\alpha$-Quartz to the high pressure rutile structure results at $10 \mathrm{GPa}$, but the $\alpha$-Quartz like structure of $\mathrm{GeO}_{2}$ occurs at $2 \mathrm{GPa}$.

Miller et al. ${ }^{9}$ was the first to report on the phase diagram of $\mathrm{SiO}_{2}$ and $\mathrm{GeO}_{2}$ solid solutions (Fig. 2). The solid solutions of different compositions were obtained by hydrothermal recrystallization with $\mathrm{SiO}_{2}$ and $\mathrm{GeO}_{2}$ precursors in sealed capsules at $70 \mathrm{MPa}$. The maximum miscibility of germanium in the Quartz lattice was found to be $31 \mathrm{wt} \%$ at $700^{\circ} \mathrm{C}$. If $>31 \mathrm{wt} \%$, Germanium appears in the form of rutile with co-ordination number 6 , then the lattice of $\mathrm{SiO}_{2}$ cannot accommodate $\mathrm{Ge}$ with co-ordination number 6 in thermodynamic conditions. It has been verified by thermal analyses that the addition of germanium even in minute quantities such as 0.1 changes the transition temperature of $\alpha$ Quartz from $573^{\circ} \mathrm{C}$ to $660^{\circ} \mathrm{C}$. In contrast to the well-developed crystal growth technique of Quartz, there are very few details on the growth of $\mathrm{SiO}_{2}-\mathrm{GeO}_{2}$ solid solution systems. The conventional flux technique used for the growth of $\mathrm{GeO}_{2}$ cannot be employed due to the poor solubility of $\mathrm{SiO}_{2}$ under these conditions. On the other hand, traditionally used crystal growth method of quartz which necessitates the use of mineralizer will reduce the incorporation of $\mathrm{Ge}$ in the $\mathrm{SiO}_{2}$ matrix by precipitation of compounds like germanate. Further due to the difference in the solubility limit of $\mathrm{SiO}_{2}$ and $\mathrm{GeO}_{2}$, it makes the growth of these crystals very delicate and complicated by the hydrothermal method. In addition, to date no structural refinement of the $\mathrm{SiO}_{2}-\mathrm{GeO}_{2}$ has been reported, which makes it even more complicated to know about the problems arising due to the inhomogeneity of the composition. Obtaining crystals of $\mathrm{SiO}_{2}-\mathrm{GeO}_{2}$ will not only help us to know the crystal chemistry but also to improve the piezoelectric properties by adjusting the concentration of Germanium in the lattice of quartz. Solubility of Quartz in water is low, hence mineralizers such as $\mathrm{NaOH}$ leads to the impurities such as sodium in the crystal and formation of germanate of sodium.

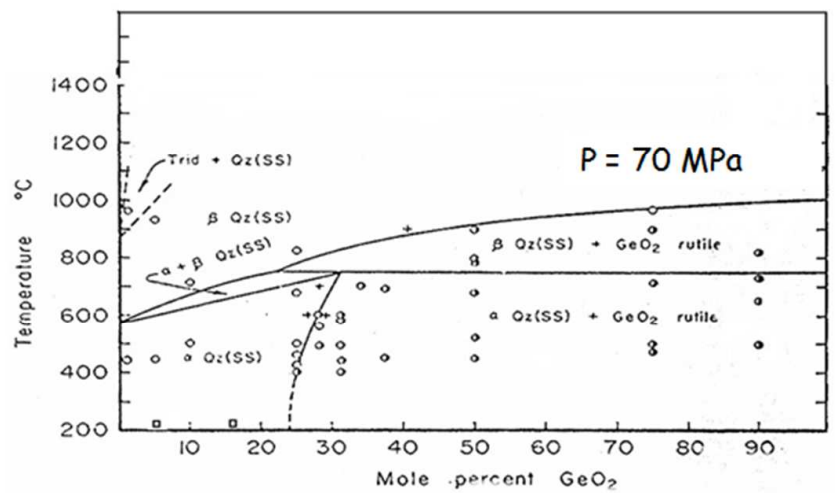

Figure 2. Phase diagram of $\mathrm{SiO}_{2}-\mathrm{GeO}_{2}$.

In the family of materials such as $\mathrm{XO}_{2}(\mathrm{X}=\mathrm{Si}, \mathrm{Ge})$ and $\mathrm{MPO}_{4}(\mathrm{M}=\mathrm{Fe}, \mathrm{Al}, \mathrm{Ga}, \mathrm{B})$ family with $\alpha$-Quartz analogue, which is composed of either only $\mathrm{XO}_{4}$ corner shared tetrahedral or both of $\mathrm{MO}_{4}$ and $\mathrm{PO}_{4}$ tetrahedra forming a trigonal system. Previous research works have confirmed experimentally that the large piezoelectric properties of $\alpha-\mathrm{GaPO}_{4}$ and $\alpha-\mathrm{GeO}_{2}$ materials in comparison to $\alpha-\mathrm{SiO}_{2}, \alpha-\mathrm{FePO}_{4}$ and $\alpha-\mathrm{AlPO}_{4}$ compounds. The aforesaid 
materials are directly related to their structural distortion with respect to the $\beta$-Quartz structure type. $\alpha-\beta$ phase transition which appears around $573{ }^{\circ} \mathrm{C}$ in $\alpha$-Quartz $\left[\theta=144.2^{\circ}\right]$ does not occur when the tilt angle $\delta$ is over $22^{\circ}$ (leading to $\theta$ under $136^{\circ}$ ]. Similarly $\alpha-\beta$ phase transition doesn't occur in $\alpha-\mathrm{GeO}_{2}$ and $\alpha-\mathrm{GaPO}_{4}$ Crystals. $\mathrm{GeO}_{2}$ exhibits two forms of differing anion coordination around the central cation of $\alpha$-Quartz type with trigonal structure and rutile type modification in tetragonal structure ${ }^{10}$. It has been reported that $\mathrm{Si}_{0.93} \mathrm{Ge}_{0.07} \mathrm{O}_{2}$ has high piezoelectric co-efficient in comparison to $\mathrm{SiO}_{2}{ }^{8}$. It can be inferred from the phase diagram of $\mathrm{SiO}_{2}-\mathrm{GeO}_{2}$ that the maximum content of $\mathrm{GeO}_{2}$ that can form single phase is 31 at $\%$ at about $700^{\circ} \mathrm{C}$ and $70 \mathrm{MPa}$ under hydrothermal conditions. Hydrothermal quartz crystals are generally grown with $\mathrm{NaOH}(1 \mathrm{M})$ and $\mathrm{Na}_{2} \mathrm{CO}_{3}(0.8 \mathrm{M})$ at about $150 \mathrm{MPa}$ and $360^{\circ} \mathrm{C}$. However these conditions doesn't apply for $\mathrm{Si}_{1-\mathrm{x}} \mathrm{Ge}_{\mathrm{x}} \mathrm{O}_{2}(\mathrm{SGO})$, because of the formation of sodium germanate.

The temperature and the pressure in the autoclave are recorded with the help of thermocouple and sensor. The temperature ranges from $300^{\circ} \mathrm{C}$ to $500^{\circ} \mathrm{C}$ and the pressure ranges from $100 \mathrm{MPa}$ to $300 \mathrm{MPa}$ to grow the quartz single crystals with a temperature gradient between $5^{\circ} \mathrm{C}$ to $100^{\circ} \mathrm{C}$. Quartz crystals are grown on the seeds of oriented $\alpha$-Quartz single crystals, which are prepared by cleaning the surface of the seeds with $\mathrm{HF} /$. Hydrothermal crystal growth in the autoclave is dependent on the supersaturation conditions and crystal growth rate, which in turn is dependent on the kinetics between the starting compounds i.e., $\mathrm{SiO}_{2}$ and $\mathrm{GeO}_{2}$. The starting nutrient compounds based on $\mathrm{SiO}_{2}$ and $\mathrm{GeO}_{2}$ is on cristobalite type structure regarding the germanium content in $\mathrm{Si}_{1-\mathrm{x}} \mathrm{Ge}_{\mathrm{x}} \mathrm{O}_{2}(\mathrm{Ge}<0.25)$ and glass phase $(\mathrm{Ge}>0.25)$. Crystal growth experiments of $\mathrm{SGO}$, when done with $\mathrm{NaOH}$, the growth rate of quartz increases. However when the quantity of $\mathrm{NaOH}$ increases the growth increases. Formation of $\mathrm{Na}_{4} \mathrm{Ge}_{9} \mathrm{O}_{20}$ phases in the solid solution is observed, which will decrease the quantity of $\mathrm{Ge}$ in the crystal grown. When pure water is used as the solvent, the thermodynamical conditions should be varied in order to forcibly dissolve the nutrients. In the aforesaid case, high temperatures $\mathrm{T}>400^{\circ} \mathrm{C}$ and $\mathrm{P}>200 \mathrm{MPa}$ is required. In this case, the content of $\mathrm{Ge}$ is high, but the distribution is less homogeneous. The high solubility of Ge in water is one of the prime reasons for which the composition of the grown crystal can be not similar as that of the nutrient. Further with the increase of Ge content, there are some cracks observed due to the high stress due to the difference between the SGO crystal and seed interface which is $\mathrm{SiO}_{2}$ pure. The transport of species can be modified by the temperature gradient in the autoclave. A small gradient allows the transport of nutrient particles in a very controlled manner and it increases the crystalline quality, but it decreases the growth rate. On the other hand, the increase of Ge content increases the germanium content in the pure water as solvent. Bulk crystals of SGO $(\mathrm{t}=4 \mathrm{~mm})$ were obtained after a period of 2 months. Electron probe microscope analysis (Fig. 3) has confirmed the presence of Ge in the lattice of SGO.

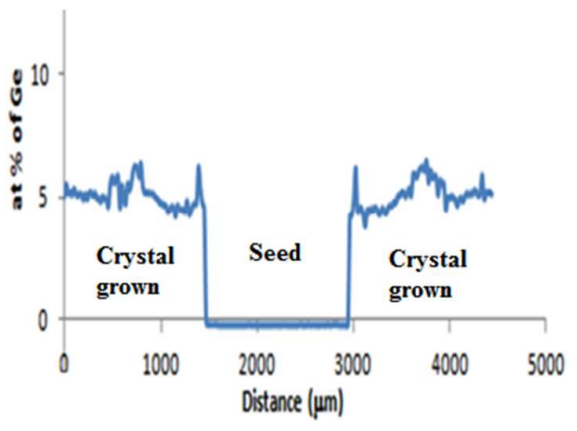

Figure 3. EPMA of the grown SGO single crystals by hydrothermal method. 


\section{CONCLUSION}

General concepts of hydrothermal crystal growth have been discussed. Usability of hydrothermal method for the growth of $\alpha$-Quartz based crystals has been demonstrated. Quartz crystals are currently well known for their remarkable properties such as piezoelectricity. By substituting "Si" ions with "Ge" is a way to increase the piezoelectricity but large single crystal has to be done. In order to construct the devices, large defect free single crystals are needed. Due to the phase transitions, hydrothermal crystal growth technique is one of the best methods to obtain large size crystals with $\mathrm{Z}$ parallel faces for piezoelectric properties. In order to grow the $\mathrm{SiO}_{2}$ doped with $\mathrm{GeO}_{2}$, it is necessary to prepare the cristobalite nutrient to obtain homogeneous composition. Further high pressure helps in conjunction with other parameters such as temperature gradient helps in obtaining $\mathrm{SiO}_{2}$ doped with $\mathrm{GeO}_{2}$. From the aforesaid, no $\mathrm{OH}^{-}$ions were found, which are detrimental for device applications.

\section{REFERENCES}

${ }^{1}$ Giorgio Spezia, (1905). Pressure is chemically inactive in the solubility and reconstitution of quartz. Proceedings of the Royal Academy of Sciences in Turin, Volume40, 254-262.

${ }^{2}$ Robert. A. Laudise, (1987). Hydrothermal Synthesis of Crystals.Chemical and Engineering News, Volume 65(39), 30-42.

${ }^{3}$ Brice, J. C. (1985).Crystals for Quartz Resonators, Reviews of Modern Physics, Volume 57 (1), 105-146.

${ }^{4}$ Gary Johnson and Jonathan Foise, (1996). Quartz, Encyclopedia of Applied Physics, Volume 15, 365-367.

${ }^{5}$ Byrappa,K. Masahiro Yoshimura, (2001). Handbook of Hydrothermal Technology Norwich, New York: Noyes Publications.

${ }^{6}$ Lignie, A., Menaert, B., Armand, P., Pena, A., Debray, J. \& Papet, P. (2013). Top seeded solution growth and structural characterizations of $\alpha$-quartz-like structure $\mathrm{GeO}_{2}$ single crystal - Cryst. Growth Des., Voume13, 4220-4225.

${ }^{7}$ Largeteau, A., Darraq, S., Goglio, G., Demazeau, G. (2008). Solvothermal crystal growth of functional materials. High Pressure Research, Volume 28(4), 503-508.

${ }^{8}$ Ranieri, V., Darracq, S., Cambon, M., Haines, J., Cambon, O., Largeteau, A. \& Demazeau, G. (2011).Hydrothermal Growth and Structural Studies of $\mathrm{Si}_{1-\mathrm{x}} \mathrm{Ge}_{\mathrm{X}} \mathrm{O}_{2}$ single Crystals, Inorg. Chem., Volume 50, 4632-4639.

9 Miller, W. Dachille, S. Shafer, F. Roy, E. C. R. (1963). The System GeO2-SiO2, Am. Mineral.Volume48, 1024-1032.

${ }^{10}$ Philippot, E. Palmier, D. Pintard, M. and Goiffon, A. (1996). A General Survey of Quartz and Quartz-like Materials: Packing Distortions, Temperature, and Pressure Effects. J. Solid State Chem., Volume 123, 1-13. 